\title{
Emerson, Lake \& Palmer: Take a Pebble (1970) - Thematic and Motivic Structure, Hints of Monothematic Sonata Form
}

\section{Filip Krejčí}

...I decided to use the European influence, but using the jazz mentality of improvisation to try to enhance these pieces.

Keith Emerson ${ }^{1}$

\section{Introduction}

Emerson's quotation is a brief description of the essence of Emerson, Lake \& Palmer music. The Emerson, Lake \& Palmer (ELP hereinafter), have been in many ways an archetypal progressive rock band: multi-movement rock suites, references to classical music and jazz, juxtaposition of spontaneus improvisation and advanced composing, overall rhythmic, harmonic and tectonic complexity are the typical atributes of their music. The immediate proximity with which the classic European classical musics heritage with African-American influences met in their creation was by far the most striking of all progrock representatives.

Take a Pebble is a typical example of the progressive rock piece. In addition, the ELP Trio did not have a rock guitarist which eliminated the disadvantages associated with writing popular music down to sheet music. Additionally, the preliminary probes show that the authors in the composition apply a motivational and thematic compositional style. Apparently, the most important attribute is that the composition has features of the monothematic sonata form, and in it, relatively pregnant - as described in the analysis itself - combines the effects of classical music and jazz.

\section{Sources for analysis}

- Official audio record, released on the first album ELP $(1971)^{2}$

\footnotetext{
${ }^{1}$ Edward Macan, Rocking the Classics: English Progressive Rock and the Counterculture (New York: Oxford University Press, 1997), 149.

${ }^{2}$ ELP, Emerson, Lake E̋ Palmer (UK: Sony BMG, 2006), [CD].
} 
- Own customized score based on the original studio record including all used instruments. Available from the link below. ${ }^{3}$

- Authorized sheet music released by MANTICORE ${ }^{4}$

Take a Pebble is the second track of the ELP debut album, released in 1970.

Keith Emerson drew primarily from Romantism. The essential consequence of this is the frequent use of leitmotifs in works based on the form of a symphonic poem (e.g. Trilogy). This legacy is also evident in Take a Pebble. However, due to the nature of the analyzed musical material, it would seem somewhat more appropriate to apply the term "main motif" as used by Richard Wagner. A distinctive motif tends to be a programming subject, for example, an opera character, while the "main theme" is in this case somewhat more compatible with a complex, integrated, purely musical idea, although a certain association with the program component is also present in this the case.

\section{Note on the origin of the score}

The score was based on an original studio record from ELP, 1970, and on the officially published Manticore edition (a publishing house founded by the ELP group members themselves).

\section{Program content of the composition, interpretation of the text and meaning of the composition as a whole}

The lyrics of vocalist Greg Lake were mostly of a character in many ways illegible thoughts, occasionally to be noted, with the features of kitsch. The text Take a Pebble in this direction is no exception. The question of the meaning of life's life is probably the most dramatic short description of the non-musical theme, the program content of this analyzed piece. The text of the exposition begins with the words "Just take a pebble and cast it to the sea, then watch the ripples that unfold in me." is a mixture of metaphorical thoughts and a comparison of life to the waves that appear when the pebble is thrown into the water (for example, "Disturbing the waters of our lives, of our lives, of our lives ...") and of multiple lyrical images "Wear sadness on your shoulders like a wornout overcoat"). It is worth mentioning the close correlation of music and text and their

${ }^{3}$ Online: https://www.dropbox.com/s/x7qqgv24626jtdq/5_1_Take_A_Pebble\%20-\%20Full\%20 Score.pdf?dl=0

${ }^{4}$ Emerson, Lake: Greatest Hits. New York: Music Sales Corp. [distributor], c1996, 1 score (79 p.). ISBN 08-256-1536-4. 
interconnection, which is one of the typical attributes of progressive rock music (for details see the analysis).

The non-music content of the composition is also related to the fact that even in terms of the organization of musical material, the composition is monothematic, indicating in some places indications of evolutionary processing. Karel Janeček writes in monothematic sonata forms: "If, on the contrary, the author wants to create a concentrated musical picture or a direct stream to the target, he will confine himself to a single thema, and if he chooses for the sonata form, he composes it monothetically. This applies both to music with a certain (or identifiable) theme and to music without a stated theme: the type of form is always given by the idea of origin and the creative intent." 5 In this case, the non-musical subject is clearly understood in terms of the organization and structure of the musical material including work with the theme, motifs, and the analysis itself.

\section{Instrumentation}

The instrumentation used to be quite auspicious in ELP production, it was only a trio. In the case of Take a Pebble, the cast is as follows: singing lead vocal (Greg Lake), piano (Keith Emerson), bass guitar (Greg Lake), drums (Carl Palmer). Roughly in the middle of the song, Greg Lake plays a solo section with a 12-string acoustic guitar, which is not very important in a musical-form respect, but it is a very important part from the program point of view, as it is explained later on.

\section{Structural walkthrough}

The introduction draws on the main theme both harmonically and motivically. Therefore it was marked with a lower index A. The first half of the phrase (the first four repeated measures) is provided only by the piano using the technique of playing with a guitar pick directly on the strings of piano. Keith Emerson's contribution to innovation in rock music sound is well known and this is one of the evidences. One of the fields he contributed to (apart from being one of the first to use synthesizers) was the extension of approach to musical instruments. In classical music, such approach like John Cage's prepared piano and other various alternative methods of getting new sounds were already well-known, but it was unusual and innovative in rock music.

\footnotetext{
${ }^{5}$ Karel Janeček, Hudebni formy (Praha: SNKLHU, 1955), 355.
} 


\section{Analysis}

Structural schema (compatible with the score, see above)

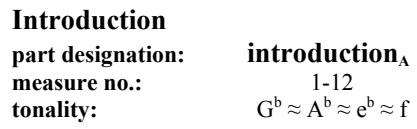

\section{1st DEVELOPMENT}

part designation:

\section{$\mathbf{X}$}

$\begin{array}{lccc}\text { bar no.: } & 54-89 & 90-101 & 101-107 \\ \text { tonality } & \mathrm{f} \text { dorian } \approx \mathrm{f} \approx \mathrm{B}^{\mathrm{b}} \approx \mathrm{F} & \mathrm{D} \approx \mathrm{d} \approx \mathrm{B}^{\mathrm{b}} \approx \mathrm{d} & \mathrm{d}\end{array}$

CONTRAST EPISODE (motivically unrelated interlude) part designation:

B

$\begin{array}{lcc} & & \text { connector }_{3} \\ \text { bar no.: } & 108-179 & 180-184 \\ \text { tonality } & \mathrm{D} & \mathrm{D} \approx \mathrm{F}\end{array}$

2nd DEVELOPMENT (jazz-influenced quasi-impro section)

$\begin{array}{lcccc}\text { part designation: } & \mathbf{X}_{\mathbf{2}} & & \mathbf{X}_{\mathbf{2}}, & \\ \text { bar no.: } & & \text { intermezzo } & & \text { connector }_{\mathrm{A}} \text {, } \\ \text { tonality } & 185-265 & 266-277 & 278-431 & 432 \\ & \mathrm{~F} & \approx & \mathrm{F} \approx \mathrm{f} \approx \mathrm{f} \text { dorian } & \mathrm{c}\end{array}$

\section{THEME (recapitulation)}

\section{part designation:}

bar no.:

tonality intro $_{A}$,

433-440

$\mathrm{e}^{\mathrm{b}} \approx \mathrm{f}$

$\begin{array}{cc}\text { a'” } & \text { A' } \\ 441-448 & 449-456 \\ \mathrm{e}^{\mathrm{b}} \approx \mathrm{f} & \mathrm{a}^{\mathrm{b}} \text { mixol. }\end{array}$

\section{Coda}

part designation: $\quad \operatorname{cod} a_{A}$

bar no.: 457-463

tonality

$$
\mathrm{e}^{\mathrm{b}} \approx \mathrm{e}^{\mathrm{b}} \text { dorian }
$$




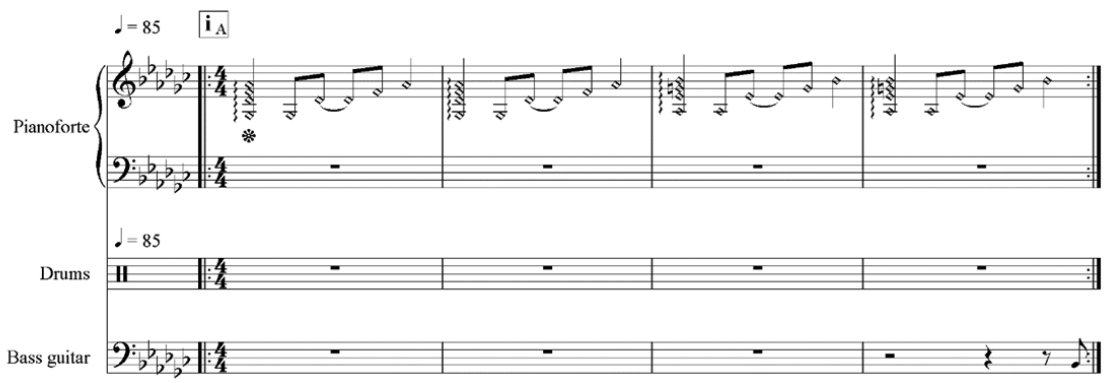

\section{Example 1}

The technique used in the introduction was that the left hand played the chords on the first beat of each measure, whereas the right hand simultaneously played the melody directly on the piano strings, using the guitar pick or simply fingers. The avoidance of sustain pedal caused that only the strings within the given chord have sustained: g-flat $+\mathrm{d}-\mathrm{flat}+\mathrm{f}+\mathrm{a}-\mathrm{flat}-\mathrm{a}$ "slash“ chord $\mathrm{D}^{\mathrm{b}} / \mathrm{G}^{\mathrm{b}}$ and then the same tones transposed the whole tone higher (a-flat $+\mathrm{e}-\mathrm{flat}+\mathrm{g}$ $+\mathrm{b}$-flat resulting in $\mathrm{E}^{\mathrm{b}} / \mathrm{A}^{\mathrm{b}}$ chord. The sound of such a distinctive dissonance (a major fifth chord slashed by the 4th degree in bass - so called ,avoid note“ within jazz music) was Emerson's typical one (see also Trilogy, Endless Enigma and many others). The notes played using the pick technique are distinguished in the score by a square notehead.

The repeated first 4 bars are the first part of the introduction. The motif of the first two bars (in G-flat major) is then transposed by a whole note (A-flat major). The following music content draws from this progression, where the first 4 bars are repeated without change in piano followed by entering drums and primarily bass guitar with the motivic outline of the main motif of the whole compostion (the 5th and 6th bar), which inclines the tonality to the parallel minor scale E-flat minor and $\mathrm{F}$ minor, respectively. In the last four bars of introduction the piano motif has been simplified just to $f+g-f l a t+b$-flat which caused the motif in bass guitar even more significant.

From the 13th bar onwards a question arises about assessment and classification of musical material. We have to ask in what conditions can we mark the analysed music as a „theme“. The most significant czech musicologist, Karel Janeček ${ }^{6}$ said that music becomes the theme after it has been „thematised“ which means that the composer must approach to this music content in athematic way in order to make it the theme. In order to find out, whether the following music

${ }^{6}$ Janeček, Hudebni formy, 102. 
is the theme, or not, we have to get deeper into the structure and correlations within the musical material. Let us consider the following music to be the theme. During the analysis, and especially at the end of the text, this hypothesis will be reflected.

The typical sign of this theme is a motif of ascending fifth in terms of melody progression and syncopation in terms of rhythm. Those have been already outlined during introduction as well as accompanying harmony - tonic minor chord with added 2 nd degree (f) in bar 14 . The piano definitively leaves the picked technique of playing on strings and continues „traditionally“ using keys - the noteheads are standard in the score. The main musical and non-musical idea is in the vocal part, although the main motif appears in both the vocal and the bass guitar.

The form of the theme is $\mathbf{a}-\mathbf{b}-\mathbf{a}$ '- $\mathbf{b}$ ', where phrases $\mathbf{a}$ and $\mathbf{b}$ are motivically related - the characteristic ascending fifth in melody and a syncopation again,but there is also a contrast between them which presents harmony, melody, dynamics, timber and different modes $-\mathbf{a}$ is in E-flat dorian and $\mathrm{F}$ dorian and phrase $\mathbf{b}$ is in A-flat mixolydian.

The duration of phrase a is eight measures and its structure is symmetrical, made of $2 \times 4$ bars, each one also divisible into $2+2$ bars. Two modes are present: E-flat dorian (bars 13 and 14) and F dorian (the following two). The main motif is present in bass guitar and is complemented by presenting the main theme also in lyrics "Just take a pebble..." which also draws from the motif - ascending fifth and syncopation. The same progression can be seen in the second half of the phrase transposed one whole-step higher into F dorian. 

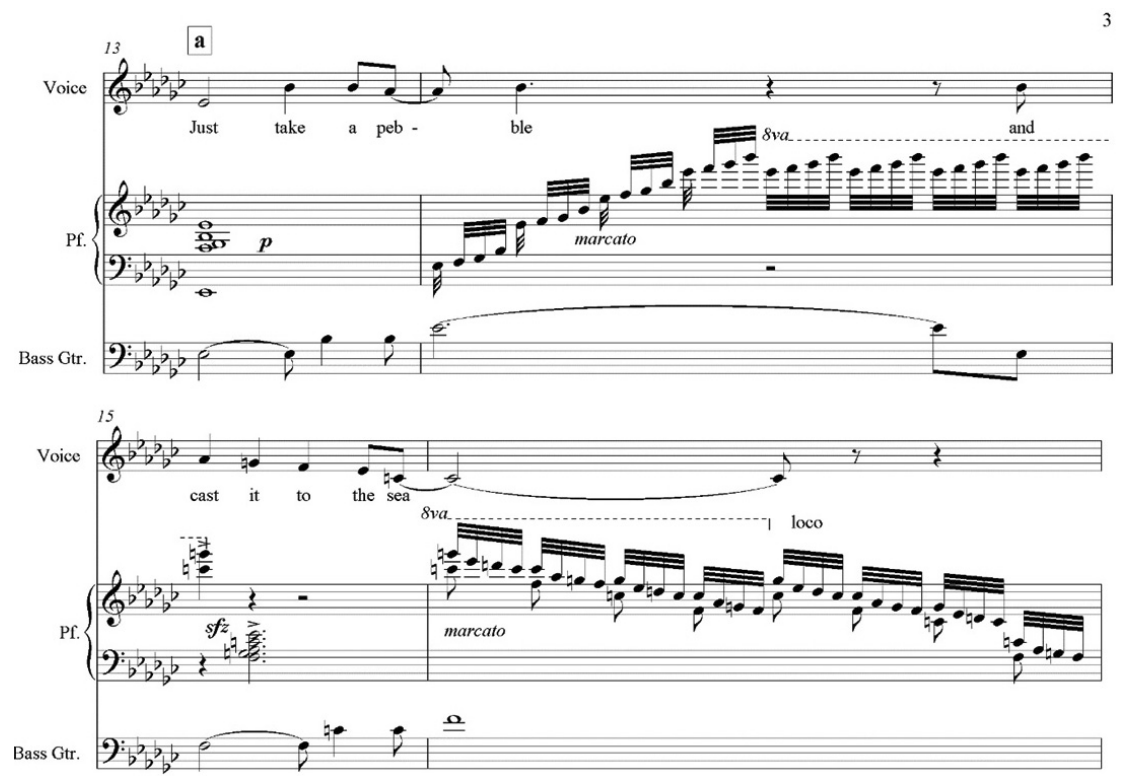

\section{Example 2}

The principle of contrast is used in the first four bars of exposition in melody, therefore in accompaniment. The piano stays for the whole 13th measure on a single chord, which is followed by a sequence 32th-note ascending run (an eclectic reminder of romantic, Rachmaninoff-like piano styles) while harmony stays on the first degree. This is not a dialogue of lead vocal and piano, but rather a piano ilustration of what is declared in the lead vocal - throwing a pebble into the water and watching the waves. The next two measures are motivically related, although transposed whole-step higher into $\mathrm{F}$ dorian. The contrast is present in dynamic (piano - marcato), in rhythm (the note values: whole - 32th), in melody (in 14th bar it ascends, then, in 16th it descends). The bass guitar corresponds with the lead vocal and makes counterpol to the piano - when the piano has 32 th notes run, it stays on one note. The whole four bars repeat with some subtle changes and of course different lyrics 

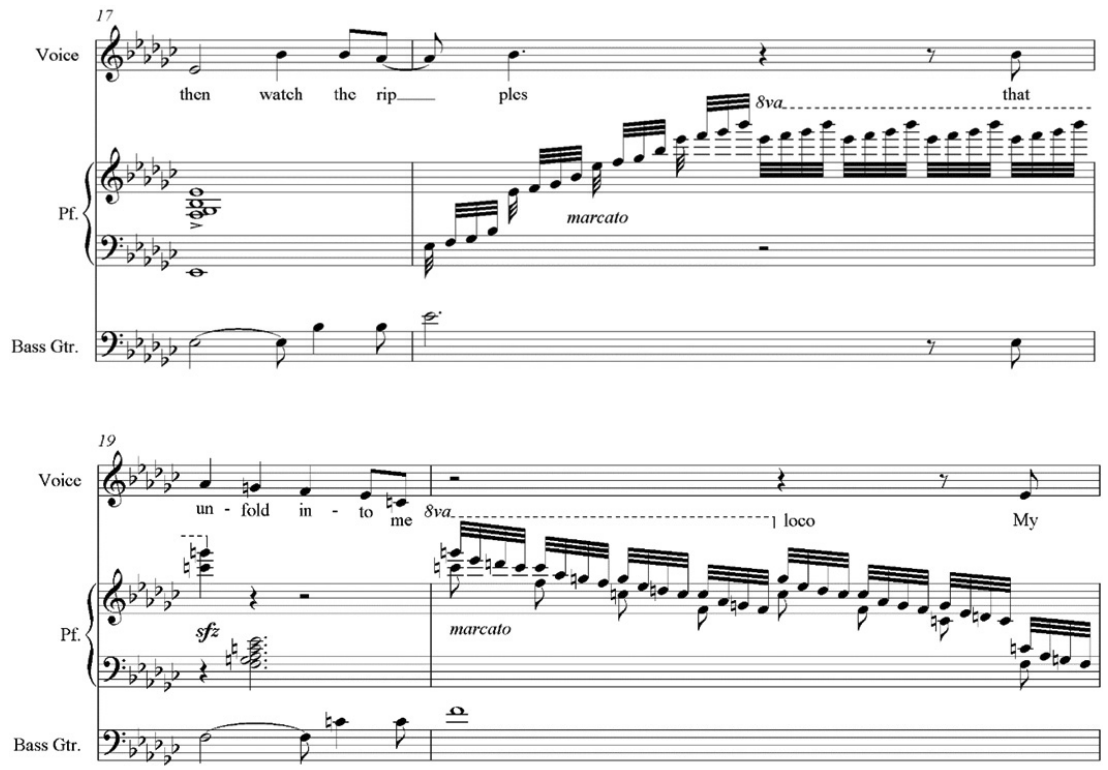

\section{Example 3}

After the first eight bars of phrase $\mathbf{a}$ comes a contrast idea $\mathbf{b}$. The key changes into A-flat mixolydian (see bar 23). The contrast to a lies not only in the different key but also in the different harmony progression, piano illustration - piano leaves the fast romantic runs and draws back to subtle motivically related ideas like for instance two fifths built vertically on top of each other (bar 22).

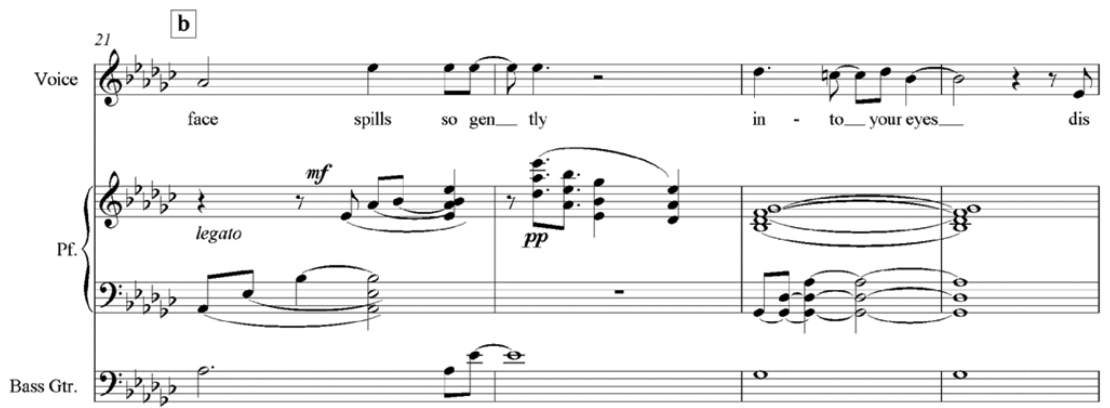

\section{Example 4}


The phrase graduates dynamicaly at the end and is finished by the fifth chord E-flat major, slashed by a-flat - the characteristic „Emerson“ dissonance. The E-flat major chord is a dominant in A-flat key, but it slowly becomes a tonic (with the Piccard third) when the E-flat minor key is returning.

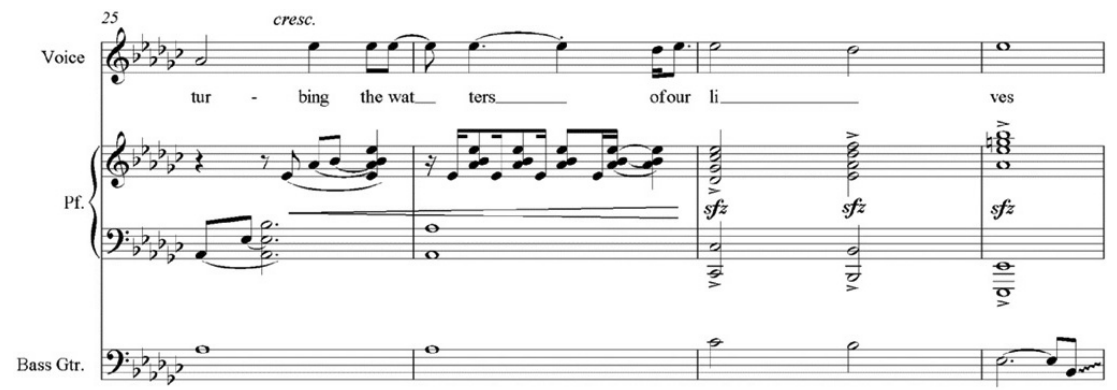

Example 5

As we stated above, the unifying idea of the two phrases $\mathbf{a}$ and $\mathbf{b}$ is a motif of ascending fifth, which is applied in the melody of the lead vocal and the bass guitar. The dynamics of the phrase $\mathbf{b}$ is more gentle, harmony is major, the lead vocal is more pronounced and in higher registers and the whole musical material graduates into the final sequence of three accented chords. Follows short connector (bars 29-32) whose purpose is to establish back the E-flat minor key. The connector draws motivically from the main motif (bass guitar) and the two phrases $\mathbf{a}$ and $\mathbf{b}$ are repeated in slight variation in piano accompaniment and new lyrics.

Back to what has been stated at the beginning of the exposition. The section $\mathbf{A}$ has been marked as an exposition of the theme, because it exposes the musical as well as the programme ("just take a pebble and cast it to the sea...") content of the song. This exposed material is thematised later in the song, which means that the composer Keith Emerson conveys the musical idea in terms of the motivical-thematic way. He brings some quotations of the motifs, as well as contrast and the whole part can be accessed like a truly coherent musical idea.

Following four bars have a function to introduce the listener to the very new, clearly contrastic, big part. This connector represents entirely new musical material and also establishes new tempo of $195 \mathrm{bpm}$ and a new key F minor.

The bar 54 is the beginning of the part marked as $\mathbf{X}$. The whole part is instrumental and the main bearer of musical ideas is the piano. The musical 
material is based on ostinato $f-c-g-c-f-b-f l a t-c-g$ in left hand of the piano, first introduced in bar 54 .

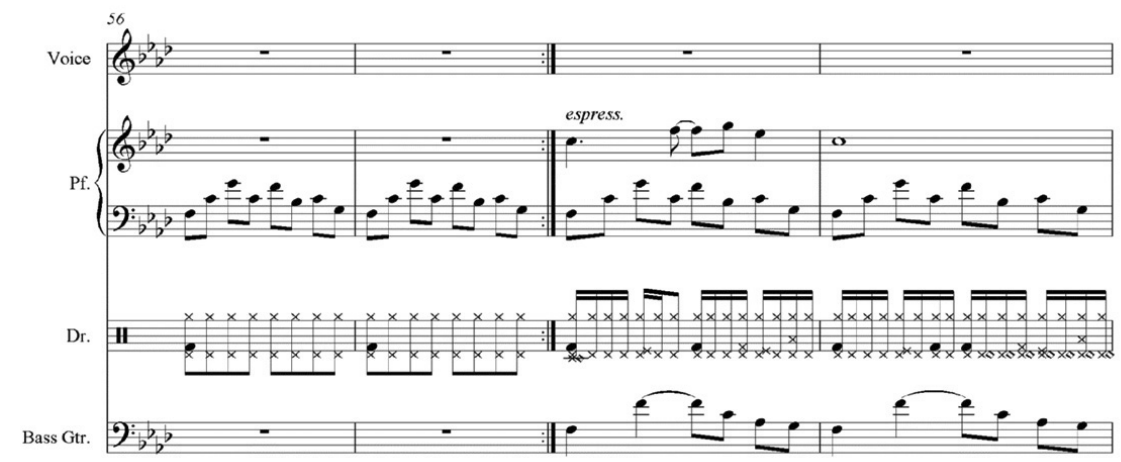

\section{Example 6}

In the bar 58 there is a rhythmical and partially melodic reminiscence of the main motif. This variation was created by the combination of the bass guitar motif and lead vocal of the first bar of exposition (bar 13). The characteristic sign is syncopation and a perfect interval (this time no perfect fifth, but fourth, followed immediately by the fifth).

This motif is extended with the melodic particle in the 61th bar. The characteristic sign is again the perfect fifth. The last three notes of the 60th bar and the first three notes of the $61 \mathrm{st}$ bar are in a way layered fifth chords $\mathrm{C} \mathrm{mi-}$ nor and B-flat major. The parallel fifths are hidden in the melodic progression. Nevertheless, immediately in bars 62 and 63 they are sorted in parallels in both left and right hand on the third and the fourth beat. These two intervals vertically built on each other are resulting in chords $\mathrm{D}^{\mathrm{b} \text { maj7 }}$ and $\mathrm{Cm} 7$. 


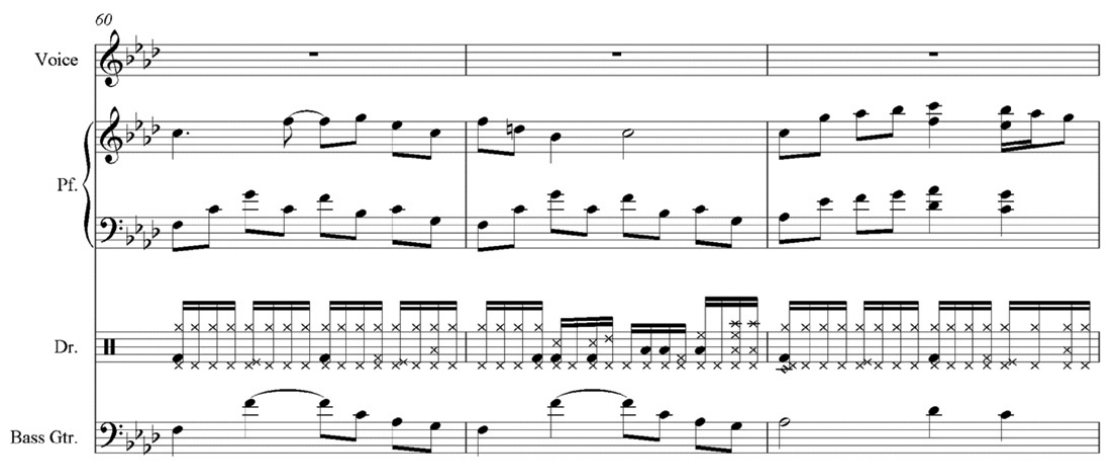

\section{Example 7}

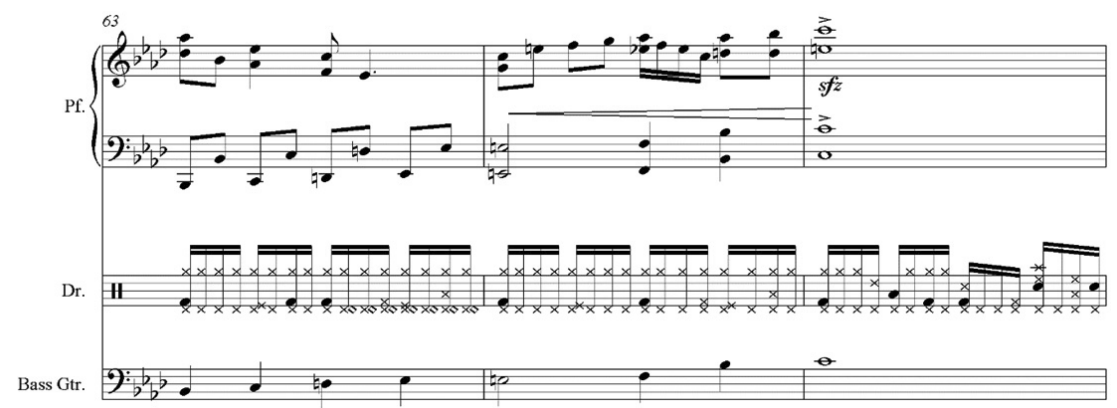

\section{Example 8}

From the 62 bar onwards the musical material tends to be tonally unstable which is one of the signs of development. Bar 62 is a short deflection to A-flat major, followed by chromatic progression in left hand in the next two bars.

From the 63rd bar we can see one of the Keith Emerson's typical progressions - left and right hand arranged in contrary motion (which can be seen also in bar 68) ending up with chromatic lift e-flat $=>$ e in the 65 th bar. Follows the whole-measure stoptime on dominant chord, again contrary motion and in the 67 th bar a tritone dominant substitution sequence with accents and tritone and respectively interval in right hand - a typical lick for jazz. 


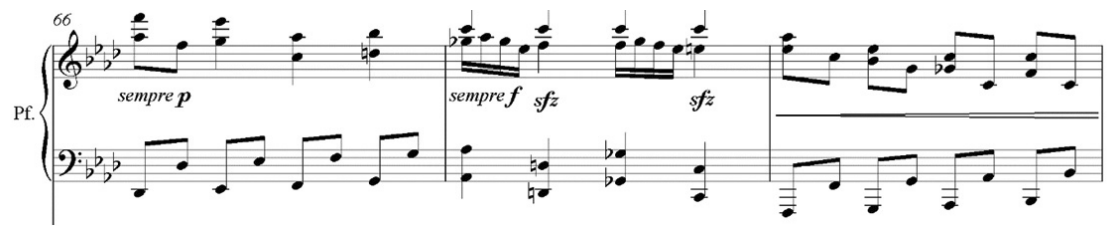

Example 9

From the 70th bar Emerson reworks the main theme to F-major key. The first development is ended, again, with the characteristic major chord with added the 4th degree dissonance. Follows the intermezzo which function is to calm down the dynamics and bring the key to $\mathrm{D}$-minor. In the right hand we can see the hints of the main motif and follows a short connector played directly on piano strings - a reminiscence of the introduction and logical closure of the section $\mathbf{X}_{2}$.

The following section of bars 108-179 would probably be the best to describe as a mere episode or insertion, even though it is a relatively large section of the composition. It is, however, extensive only by the number of bars and the time duration, not the musical content itself. "Insertion (episode) is a composer almost as if it was a creative whim and its release is not connected with the composition of the song." 7

The only aspect that, nevertheless, points to the interconnectedness of this interplay with the rest of the song is the programme content - the lyrics. Behind this dynamically very insignificant embedded music is heard the splash of water, which most likely means that this episode represents circles in the water, which are the main programming theme of the song. From the point of view of tectonics and meaning, we could compare this interplay to the second movement of Vivaldi's third violin concerti, "Autumn", which is also dynamically very constant, outrageous, and only represents the tired and sleeping hunters.

Probably the most significant atribute of this episode is its sharp contrast to the rest of the musical material of the composition. The contrast is present in tonality, rhythm, tempo, dynamics, instrumentation and of course motivically and thematically. Greg Lake's interpretation brings signs of blues and most probably it is his own composition, programmatically related to the rest of the song Take a Pebble.

Another connector brings not only the key back to F-major, but also brings back the previous instrumentation, dynamics and tempo. The next section, $\mathbf{X}_{2}$, marked as a $2^{\text {nd }}$ development has a character of quasi-jazz improvisation that

${ }^{7}$ Janeček, Hudebni formy, 85. 
uses and transformates the motifs from exposition which are arranged mostly assymetrically.

Much jazz improvisation is based on ostinato figure, in jazz commonly called the riff. Keith Emerson liked it and used it in many of his improvisations. The ostinato in lefthand was already introduced at the beginning of the first development, the character of the figure itself was probably derived from the main theme. As has been said earlier, its significant intervals are two vertically placed fifths.

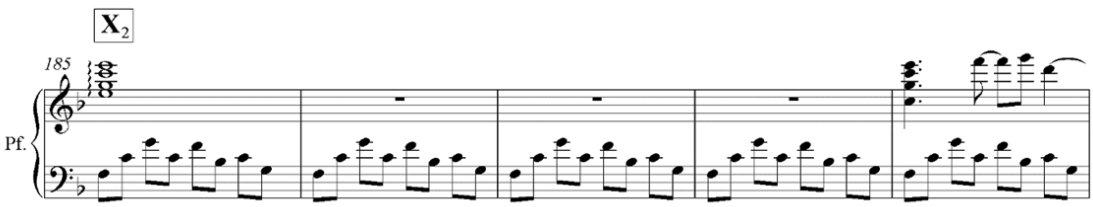

Example 10

The second development, $\mathbf{X}_{2}$ brings the musical flow after the contrast episode $Y$ to the tempo and rhythm presented in the first development, $X_{1} \cdot X_{2}$ begins with a reminiscence of the first motif of the development (bar 58 and 189 respectively), and is followed by its variations (bar 192, 193, 208, 232), diatonic runs $(240,241$, 247-252) and some common jazz licks (bars 234, 236, 238, 239). This section slightly reminds the compositional style used by Chick Corea when working on his cycle Children Songs - ostinato pattern in left hand and ornamental drawings of motifs variations in right hand. When we take into consideration that jazz influences, in Keith Emerson's composition were very common, it is no doubt that use of this style was an intention.
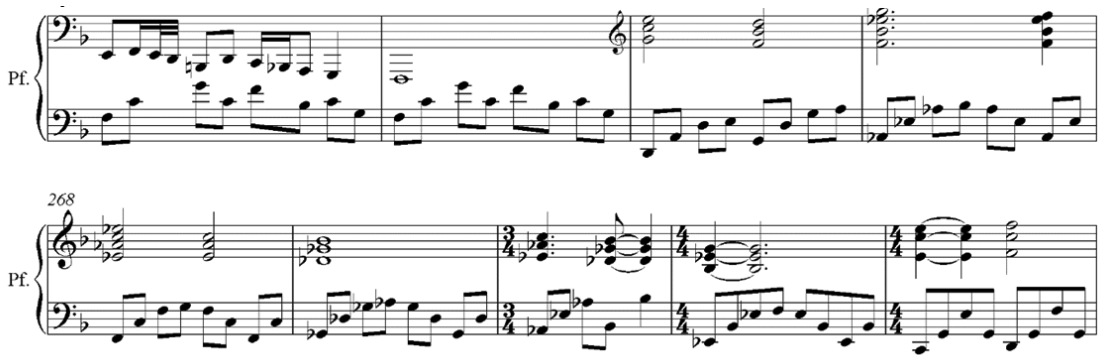

Example 11 

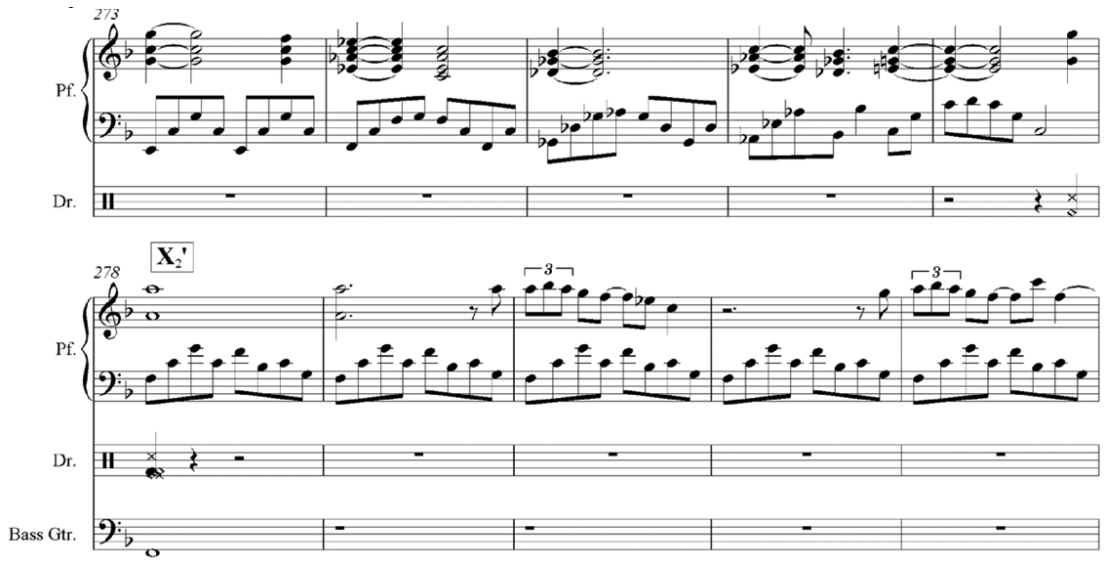

\section{Example 12}

In the 266th bar begins the non-improvised intermezzo which brings a fresh air into the flow, contrasting rather monotonous musical material used in previous bars - the ostinato changes and music modulates into E-flat major borrowing tones from even more distant keys from the previous F-major. Keith Emerson used this intermezzo as a transition episode in his later piano improvisations. The 270th bar has been shortened to $3 / 4$ meter. This causes a short confusion of the listener's sense of rhythm which is caused by switching the downbeat and upbeat. This little detail plays very important role in the whole complexity - the contrast of the transition section is even more pronounced.

Though the ostinato is coming back with the new section $\mathbf{X}_{2}^{\prime}$, the contrast is still present in instrumentation - the bass and drums are added. From now on, it is in terms of jazz realms a full-featured jazz trio. Although this section still feels to be a jazzy improvisation, it is definitely more composed than just improvised and from the general musical form point of view the section plays a very important role.

In bars 292-293 and 295-296 the bass corelates with the diatonic gesture in piano which repeates the classic jazz tritone-acacciatura lick. The bass then stops on the first degree (f), where it stays and piano the plays the 8th runs which creates a small sign of dialogue between the two instruments. 


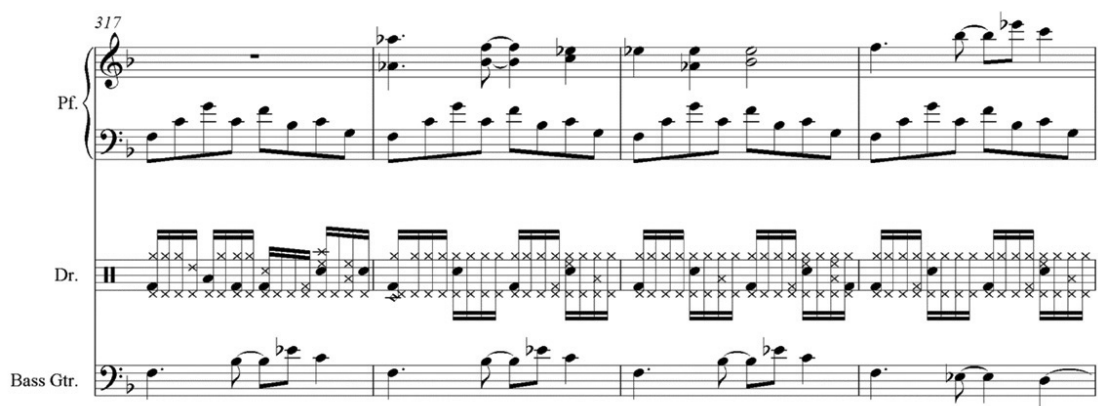

Example 13

In bars 316-320 we can see the variation of the main motif in the bass guitar and then in the piano in bar 320, as a response. The motif is then developed up to the 331th bar. The following musical material gradually increases the dynamic level and even the harmony gets more dissonant, using denser and accented jazz chords as in bars 336-344. This brings the overall concept even closer to classical jazz. In the 345th bar Emerson turns back to the main motif.

From the 370th bar Emerson leaves again the ostinato figure to bring it back again after a short while, in bar 384. From this point, the material again turns to be more improvisation, than a composition and by the end of the whole section the dynamics very subtly and slowly decreases and then finally stops on bar 431 . The 32th note F-dorian rundown then segues to the recapitulation of the theme.

Concerning the overall characteristics of section $\mathbf{X}_{2}^{\prime}$, there is a thought gap between Karel Janeček's musical form paradigm, who strictly pointed improvisation and development against each other. There are two possible answers to this question:

1) The $X_{2}$ ' section is not just a free improvisation but it is to some extend composed.

2) Even a free jazz improvisation can be very well understood as a stream of musical material of evolutionary character: work with motifs, themes, frequent modulations, numerous runs, sequencing, polyphony, bitonality etc. All of this is absolutely essential for jazz improvisation.

The $\mathbf{X}_{2}$ ' section partially fulfills these criteria. The described musical material illustrates that sometimes it is not possible to set a sharp boundary between the composition and instant improvisation. While some sections are probably purely 
improvisational (e.g. bars 278-292), other sections are in turn intentionally musically formed and developed (e.g. bars 365-377 and others).

In recapitulation $\left(\mathbf{A}^{\prime}\right)$, there is a slight modification of the piano accompaniment, which no longer contains the wild 32th sequences, but it is apparently quieter and calmer not only in terms of dynamics but also tonally. The whole style of piano accompaniment tends to be more tonally stabble which helps to establish the tonic and thus can be understood as a confirmation of an original key. As for dynamics only in bar 454 a slight gradation is noticeable. This phenomenon can be understood as a hint of tonal nivelisation. The harmony and tonal walkthrough is kept the same as the exposition during the whole duration.

Coda contains a repeated and more dynamically exposed idea from the conclusion of the small sentence b, i.e. from the end of the subject. The last tattoos conclude the whole song with a vocal tone with a piano sequence similar to the exposition that harmonically reverts to $9^{\text {th }}$ chords (similar to the introduction).

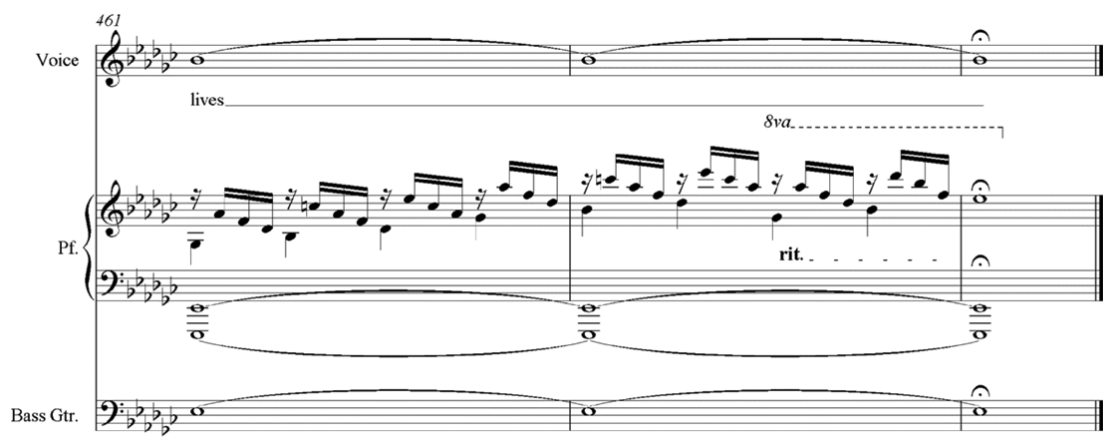

Example 14

\section{Melodics}

A characteristic melodic progression not only for the main theme, but for the whole song, is one or two rising perfect fifths which results to the interval of the major ninth from the initial note, harmonised by the ninth chord. The ninth chord appears firstly already in the introduction: 


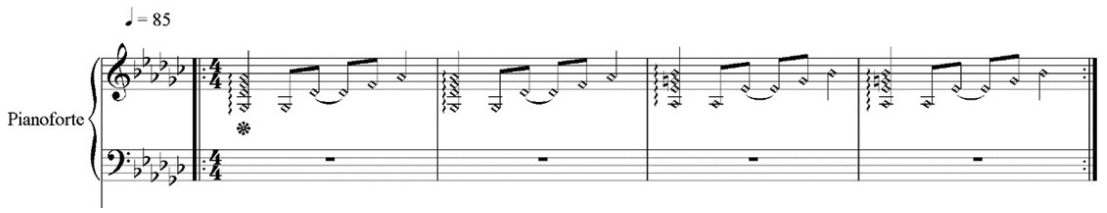

\section{Example 15}

The interval of the perfect fifth is a significant essence of the whole composition. The very first measure of introduction uses chord $D^{b} / G^{b}$ ( $g$-flat, $d-$ flat, $f$ and a-flat), which contains two perfect fifths built upon each other. The essence of perfect fifth is present not only in melody of the theme (mainly the very first interval of lead vocal), but also in harmony of the accompaniment (e.g. the introduction or bar 22 in piano and many more). This essence is thus present in horizontal (melodic) approach as well in vertical approach (harmony) and is to be found throughout the whole composition.

Also the ostinato figure which is used as the riff in both developments, begins with the two ascending perfect fifths ( $\mathrm{f}-\mathrm{c}$ and $\mathrm{c}-\mathrm{g}$ ) (bars 54 and 185). But the figure continues with another perfect fifths, this time descending $(\mathrm{g}-\mathrm{c}$ and $f-b$-flat).

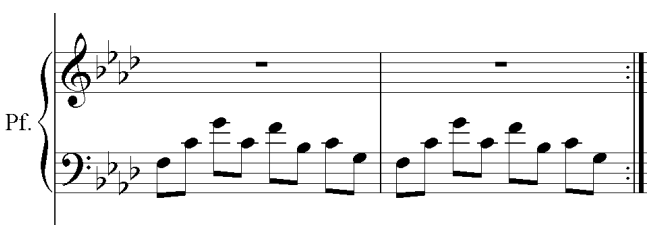

Example 16

The bass guitar enters in the 5th bar also using the rising perfect fifth (eflat-b-flat):

Bass Gtr.

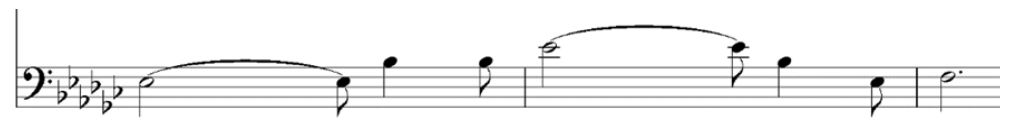

\section{Example 17}

As for the main theme, the quintessential mark is the contrast which is present in all of the components of the musical material: 

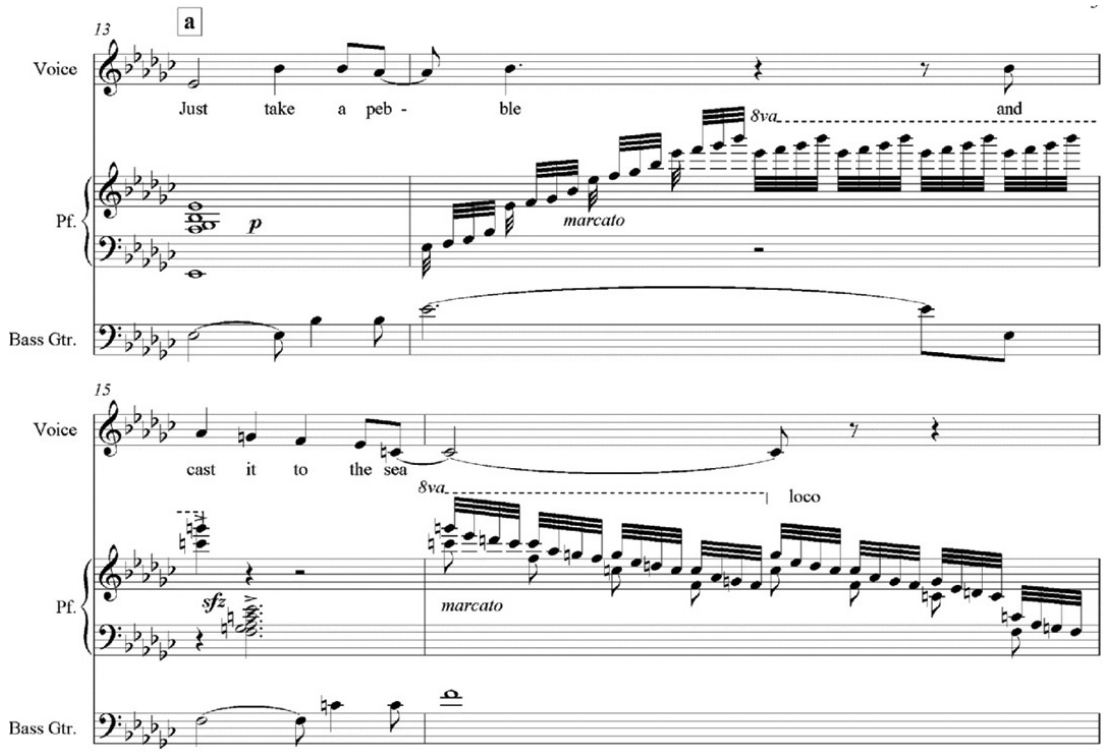

\section{Example 18}

The melodic progression of the first phrase (a) of the main theme is also based on a principal of contrast. The ascending fifth in the 13th bar is contrasted by descending seconds in the 15 th bar. The contrast is underlined by accompanying piano which reacts to the first melodic particle in the 13th measure by ascending progression and then, in 16th bar as opposed to the lead vocal melody, descending.

The second phrase, $\mathbf{b}$, also starts with ascending perfect fifth (a-flat - e-flat) in leading vocal, but modulates to A-flat mixolydian. The accompanying harmony in piano again consists of the two perfect fifths built upon each other (bars 21 and 23 in left hand and bar 22 in right hand). 


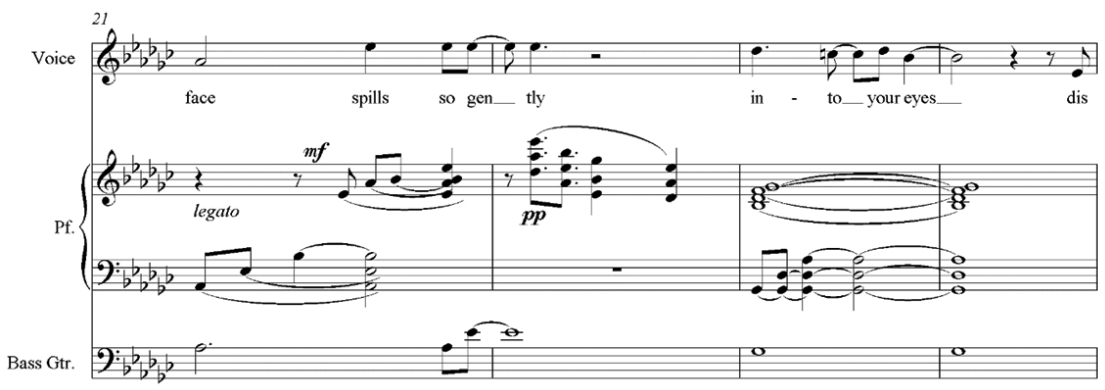

\section{Example 19}

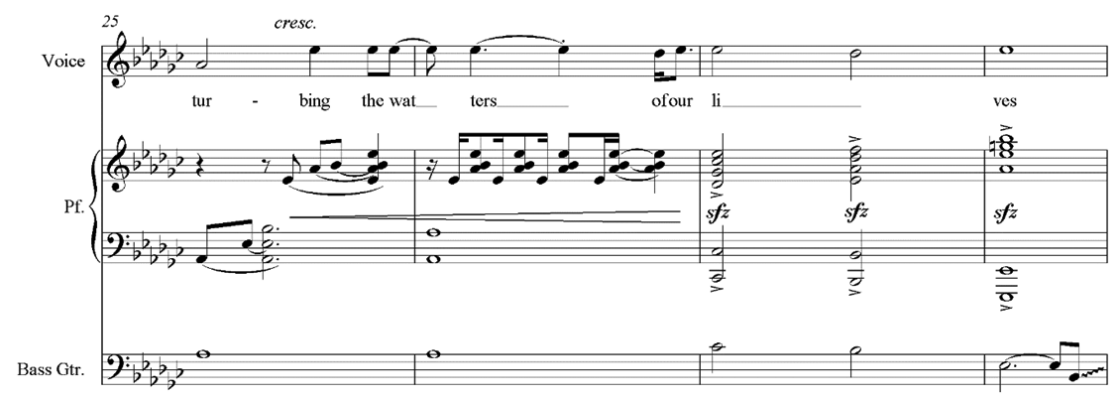

\section{Example 20}

Even in sections functioning only as a connecting music, the essence of the perfect fifth is present (this time in left hand):

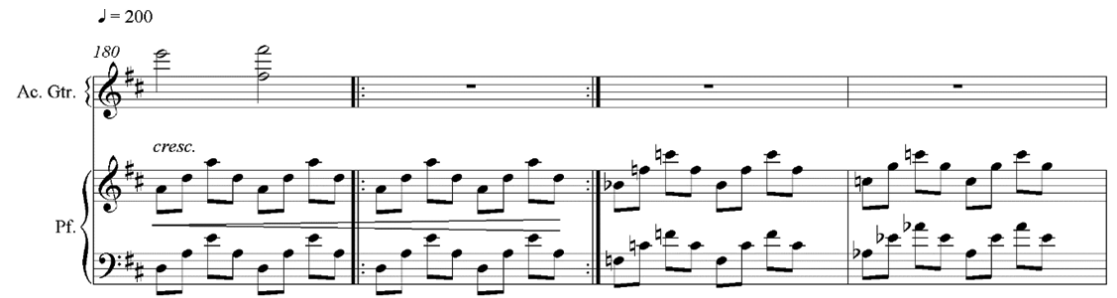

\section{Example 21}

The ascending perfect fifth is even in the last melodic piece of the song, at the very end of the song, at the 460th bar (in lead vocal). Given the evolution of the song so far, it is undoubtedly not a coincidence but an intention. 


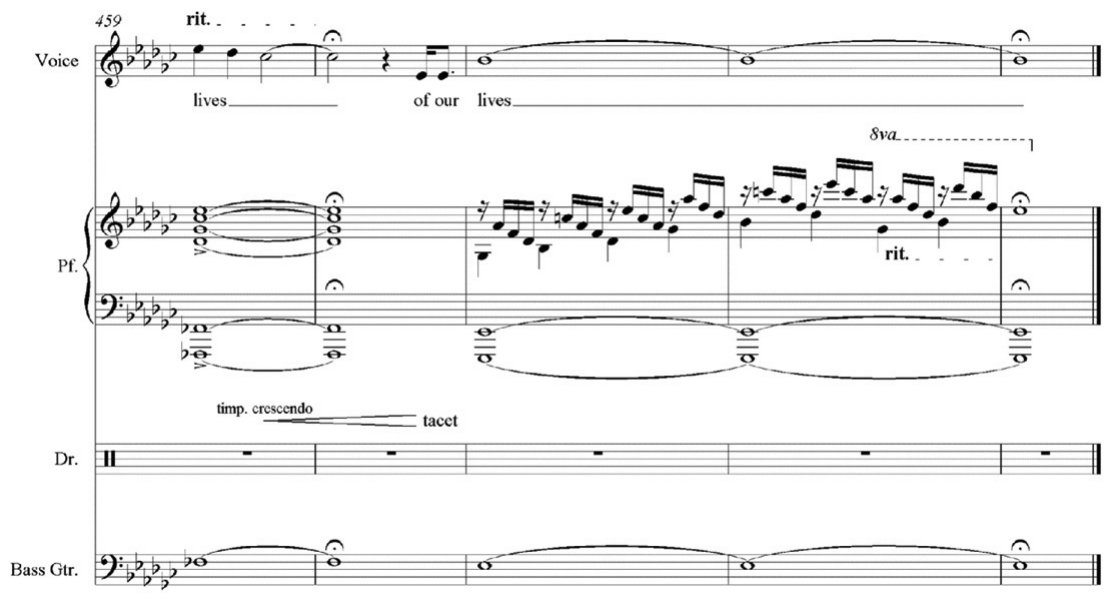

\section{Example 22}

\section{The kinetic component of the composition}

The main rhythmic feature of the main theme of the song is the syncope in its main theme, very often connected with the already mentioned ascending perfect fifth:

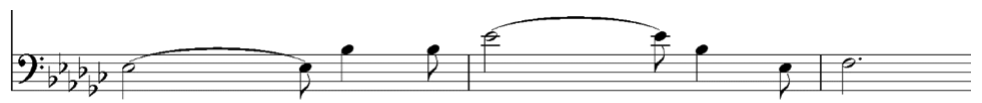

\section{Example 23}

This rhythmic pattern appears throughout the length of the composition, in each phrase except for the contrasting episode $\mathbf{B}$. The most important building element is then in the development (e.g. in the $\mathbf{X}$ section (bars 58, 60, 70, 74, $78,80,82,84,86,88$ and others) and $\mathbf{X}_{2}$ (bars 189, 208, 212, 213, 215, 221, 225, 232, 240 etc.).

The variation of the rhythm component of the main motif appears in all of these measures either in the form of at least a rhythmic reminiscence of the main motif, that is syncope, or preferably in combination with the melody - the syncopated ascending perfect fifth, like bar 225: 


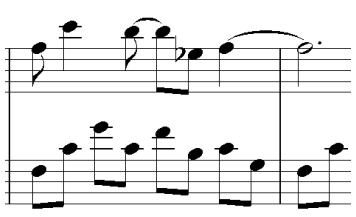

Example 24

... or with melodic variations such as bar 354 :

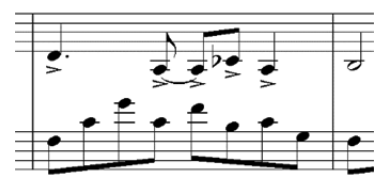

Example 25

The whole rhythm component of the song is not too complicated. From the point of view of the kinetic aspect as a whole, it is worth mentioning the contrasts in the tempo between the individual parts:

- Exposition A slowly;

- $1^{\text {st }}$ development $\mathbf{X}$ fast;

- contrasting episode B slowly;

- $2^{\text {nd }}$ development $\mathbf{X}_{2}$ fast;

- Recapitulation $\mathbf{A}^{\prime}$ slowly.

Thus, the kinetic component seems to follow its tectonics (or the way in which the tectonics of the composition are formed) and the principle of contrast and affinity is therefore applied here as well. The dynamic aspect of musical expression basically copies the kinetic component.

\section{Conclusion}

The aim of the analysis was to prove that ELP's composition method was in this case motivic-thematic, which is not very common in rock music, and that there is a number of signs of sonata form in the architecture of the song. Of course, we can not simply state without a brief comment that this is a monothematic sonata form just as in case of Joseph Haydn for instance, although a few prerequisites are met. 
In this case, the form of the composition could be interpreted as a kind of three-part form with development and a contrasting episode: $\mathbf{A}-\mathbf{X}-\mathbf{( B )}-\mathbf{X}-\mathbf{A}$, where the contrasting episode $\mathbf{B}$ is a perfect example of eclecticism and unpredictability of progressive rock music. Although all the musical material of the composition is motivically and thematically coherent and relatively detailed at all levels of the musical structure, the authors did not hesitate to place a musical idea in the middle of the song which is completely removed from the musical context and does not even form a formal element in itself.

Section $\mathbf{B}$ additionally contains audible elements of blues in both vocal and guitar Greg Lake's interpretation, while the rest of the musical material of the composition is a mixture of the influences of Romanticism and jazz. This episode, however, brings out a non-musical program idea that plays a very important tectonic role. Section $\mathbf{B}$ contains a kind of paradox of contrast and affinity. The sound of splashing water can be heard in the studio recording at the beginning of section $\mathbf{B}$. The authors (though a little bit superficially) point out that the forthcoming musical material, which is purely instrumental, deals precisely with the subject of the song - the subject in the sense of programmatic meaning - namely the circles in the water and its previously described metaphorical overlap. So at this point, on the one hand, there is a marked alienation from the point of view of the coherence of musical content, but on the contrary, the essential processing of the idea of a program based on the main theme. This, in general, comparing with what have been stated about the principle of contrast, fits perfectly with the overall philosophy of the song.

For the ELP trio, which is an archetypal example of progressive rock, Take a Pebble is a typical representative of their early creation, although it does not include a number of aspects (atonalities, rock suite forms, polyrhythms, etc.) they used later on.

\section{Emerson, Lake \& Palmer: Take a Pebble (1970) - Thematic and Motivic Structure, Hints of Monothematic Sonata Form}

\section{Abstract}

The subject of this analysis is the musical material of the progressive rock area, specifically the Take a Pebble song by the British band Emerson, Lake \& Palmer (1970). The analysis focuses on motivic and thematic coherence and the overall musical form, but also deals with substantial correlations in the field of instrumentation, harmony, rhythm, melody as well as dynamic aspect, the program content of the composition (the lyrics), interpretation style and other contexts. 


\section{Emerson, Lake \& Palmer: Take a Pebble (1970) - tematicko-motivická struktura, znaky monotematické sonátové formy}

\section{Abstrakt}

Předmětem zkoumání této analýzy je hudební materiál oblasti progresivního rocku, konkrétně skladba Take a Pebble britské skupiny Emerson, Lake \& Palmer (1970). Analýza se zaměřuje zejména na motivicko-tematickou koherenci a celkovou hudební formu, ale věnuje se i podstatným souvztažnostem na poli instrumentace, harmonie, kinetiky, melodiky, stejně jako dynamické stránce, programovému sdělení skladby, interpretační rovině a dalším souvislostem.

\section{Keywords}

Emerson, Lake, Palmer; ELP; complex analysis; sonata form; motivic-thematic structure; motif; theme; progressive rock

\section{Klíčová slova}

Emerson, Lake, Palmer; ELP; komplexní analýza; sonátová forma; motivickotematická struktura; motiv; téma; progresivní rock

Filip Krejčí

Katedra hudební výchovy PdF UP

Univerzitní 3-5

77180 Olomouc, Česká republika

filip.krejci@upol.cz 